\title{
Nebulised sodium cromoglycate and verapamil in methacholine induced asthma
}

\author{
A L BONER, G VALlONE, A ANDREOLI, R BIANCOTTO, AND J O WARNER \\ Villagio Alpino Pio XXII, Misurina, Clinica Pediatrica dell'Universita di Verona, and Servizio di fisica \\ sanitaria, Verona, Italy, and Paediatric Respiratory Unit, Brompton Hospital, London
}

SUMmARY Fifteen children with asthma underwent challenges with methacholine on separate days after double blind administration by nebuliser of either verapamil $(5 \mathrm{mg})$, cromoglycate $(20 \mathrm{mg})$, or saline (placebo). The provocation doses that produced a $20 \%$ fall in forced expiratory volume in one second (PD20) were analysed. There was variation in the protective effects of verapamil and cromoglycate among the patients. Although cromoglycate produced an increase in PD20 in 53\% of the children tested, the protection was not significant when compared with the placebo. Verapamil was partially protective, however, in $80 \%$ of children and achieved significantly better results than the placebo. We suggest that this is likely to be due to a direct effect on bronchial smooth muscle.

One of the characteristic features of asthma is an increased sensitivity of airways to physical, chemical, and pharmacological stimuli, such as histamine, bradykinin, and acetylcholine or its synthetic analogue, methacholine. ${ }^{12}$ Sensitivity to methacholine has become a valuable, reproducible, and widely used technique for studying irritability of the airways. $^{3}$

There have been several studies since 1981 that have investigated the value of calcium antagonist drugs in blocking asthma induced by a variety of agents, and these have produced differing results.
Studies to date have been predominantly on young adults with mild asthma. The purpose of this study was to compare the effects of the calcium antagonist verapamil with sodium cromoglycate, both administered by nebuliser, on bronchoconstriction induced by methacholine in children with moderately severe, extrinsic bronchial asthma.

\section{Patients and methods}

Fifteen children aged 7-13 years with asthma from a residential home for children with asthma (Villagio

Table 1 Details of the 15 patients who entered the study

\begin{tabular}{|c|c|c|c|c|c|c|c|c|c|}
\hline \multirow{2}{*}{$\begin{array}{l}\text { Case } \\
\text { No }\end{array}$} & \multirow[t]{2}{*}{ Sex } & \multirow{2}{*}{$\begin{array}{l}\text { Age } \\
\text { (yrs) }\end{array}$} & \multirow{2}{*}{$\begin{array}{l}\text { Height } \\
(\mathrm{cm})\end{array}$} & \multirow{2}{*}{$\begin{array}{l}\text { Weight } \\
(k g)\end{array}$} & \multirow[t]{2}{*}{ Treatment } & \multirow{2}{*}{$\begin{array}{l}\text { Duration } \\
\text { of } \\
\text { asthma } \\
\text { (yrs) }\end{array}$} & \multirow{2}{*}{$\begin{array}{l}\text { Paper } \\
\text { radioimmuno- } \\
\text { sorbent } \\
\text { test }(U / \mathrm{ml})\end{array}$} & \multicolumn{2}{|c|}{ Radioallergosorbent test } \\
\hline & & & & & & & & $\begin{array}{l}\text { Grass } \\
\text { pollen }\end{array}$ & $\begin{array}{l}\text { Dermatophagoides } \\
\text { pteronyssimus }\end{array}$ \\
\hline 1 & $\mathbf{M}$ & 11 & 140 & 32 & ISB.SCG.BDP & 10 & 147 & $1^{+}$ & $3^{+}$ \\
\hline 2 & $\mathbf{M}$ & 8 & 131 & 27 & ISB & 5 & 245 & $1^{+}$ & $3^{+}$ \\
\hline 3 & $\mathbf{M}$ & 13 & 168 & 70 & ISB.SCG.T & 5 & 1530 & $2^{+}$ & $4^{+}$ \\
\hline 4 & $\mathrm{~F}$ & 8 & 121 & 24 & ISB,SCG & $7 \cdot 5$ & 422 & - & $2^{+}$ \\
\hline 5 & $\mathbf{M}$ & 13 & 148 & 38 & ISB & 10 & 638 & $4^{+}$ & - \\
\hline 6 & $\mathrm{~F}$ & 10 & 133 & $38 \cdot 5$ & ISB.SCG & 5 & 491 & - & $1^{+}$ \\
\hline 7 & $\mathrm{M}$ & 10 & 133 & $25 \cdot 8$ & ISB.SCG & 8 & 833 & $4^{+}$ & $2^{+}$ \\
\hline 8 & M & 13 & 168 & 70 & ISB.SCG & 6 & 1490 & $2^{+}$ & $4^{+}$ \\
\hline 9 & $\mathbf{M}$ & 13 & 157 & $47 \cdot 5$ & ISB & 10 & 378 & - & $3^{+}$ \\
\hline 10 & $\mathrm{M}$ & 9 & 126 & $26 \cdot 3$ & ISB,SCG,T & 7 & 465 & $3^{+}$ & $4^{+}$ \\
\hline 11 & $\mathbf{M}$ & 12 & 155 & 54.5 & ISB & 11 & 2940) & $3^{+}$ & $4^{+}$ \\
\hline 12 & $\mathbf{M}$ & 7 & 131 & 30 & ISB.T.BDP & 6 & 1245 & $2^{+}$ & - \\
\hline 13 & $\mathrm{~F}$ & 12 & 140 & 35 & ISB.SCG & 11 & 446 & $3^{+}$ & $4^{+}$ \\
\hline 14 & $\mathrm{~F}$ & 10 & 135 & 40 & ISB & 8 & 605 & $2^{+}$ & $4^{+}$ \\
\hline 15 & $\mathrm{~F}$ & 13 & 156 & 64 & ISB,SCG,T & 5 & 295 & $2^{+}$ & - \\
\hline
\end{tabular}

ISB = Intermittent sympathomimetic bronchodilators; $S C G=$ sodium cromoglycate; $\mathrm{T}=$ theophylline; $\mathrm{BDP}=$ beclomethasone dipropionate . 
Alpino Pio XXII, Misurina, in the Italian Alps, with an altitude of $1756 \mathrm{~m}$ ) participated in the study. They all had reversible airways obstruction with skin tests positive to inhaled allergens and detectable serum IgE antibodies to at least one of three allergens (Dermatophagoides pteronyssimus, D. farinae, and grass pollen) (Table 1). None of the patients had had any upper respiratory tract infection in the four weeks before the study, which was carried out at high altitude and so minimised exposure to allergens. ${ }^{45}$ None of the children had hypotension, sick sinus syndrome, or atrioventricular block, which are contraindications to the use of calcium channel blockers. ${ }^{6}$ Treatment with beta 2 sympathomimetics and cromoglycate was stopped 24 hours before the study, while slow release theophylline was stopped for one week. No patients were on oral steroid and only two patients (cases 1 and 12) were taking inhaled steroid, which was continued during the study. The children were considered to have moderately severe asthma, because they all required regular prophylactic treatment in their home environment and, despite treatment, still had frequent severe attacks that led to excessive absence from school. At the residential school treatment requirements and severity diminished considerably.

Sodium cromoglycate $(20 \mathrm{mg} / 2 \mathrm{ml})$, verapamil $(5 \mathrm{mg} / 2 \mathrm{ml})$, or $2 \mathrm{ml}$ saline solution as a placebo were administered by a Hudson nebuliser driven by compressed air at $8 \mathrm{l} / \mathrm{min}, 30$ minutes before the challenge with methacholine, in a randomised double blind fashion. On the first day a baseline bronchoprovocation with methacholine was performed. During the next three days each patient was tested sequentially after each drug - that is, saline, verapamil, or cromoglycate. All tests were performed at the same time of day and were completed within four days. Forced expiratory volume in one second $\left(F E V_{1}\right)$ was recorded by a Vitalograph wedge spirometer before and 30 minutes after inhalation of the drug but before provocation.

Bronchoprovocation with methacholine was performed with a 'Mefar' dosimeter, which can nebulise $0.01 \mathrm{ml}$ of solution in 1.2 seconds. Thus 10 or $100 \mu \mathrm{g}$ of methacholine solution (in phosphate buffer), using a $0 \cdot 1$ or $1 \%$ solution, respectively, is nebulised in 1.2 seconds. The diameter of particles is 0.5 $3.0 \mu$. All the inhalations were performed by slow inspiration, starting from functional residual capacity without reaching total lung capacity followed by a five second holding of breath. Before the provocation with methacholine five inhalations of buffer solution were performed. One minute after the last inhalation $\mathrm{FEV}_{1}$ was recorded again and the challenge proceeded only if the change in $F E V_{1}$ was less than $10 \%$. Each patient received bronchoprovoca-

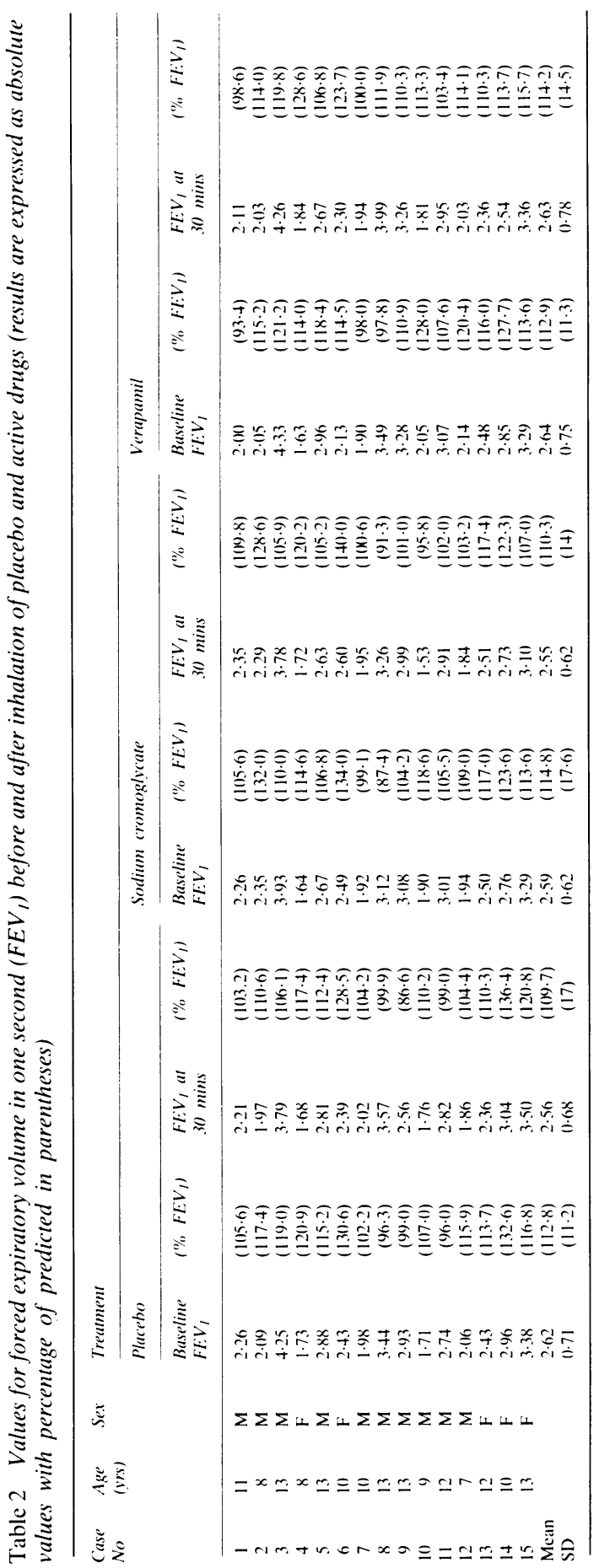


tion with methacholine by increasing the number of inhalations of $0 \cdot 1 \%$ methacholine solution to reach a total of $200 \mu \mathrm{g}$ (20 inhalations). If a $20 \%$ fall in $\mathrm{FEV}_{1}$ had not occurred the patient began inhalations of the $1 \%$ methacholine solution.

Data were plotted so that the cumulative units of inhaled methacholine appeared logarithmically on the abscissa and percentage decrease in $\mathrm{FEV}_{1}$ compared with buffer control appeared arithmetically on the ordinate. The cumulative dose of methacholine to produce an exact $20 \%$ fall in $\mathrm{FEV}_{1}$ (PD20) was calculated as described by Rosenthal. ${ }^{7}$ The results were analysed by Wilcoxon matched pairs test.

The parents of the patients gave informed consent and the protocol was approved by the hospital ethical committee.

\section{Results}

Baseline pulmonary function are presented in Table 2. Baseline $\mathrm{FEV}_{1}$ was always above $80 \%$ of the predicted values for the height and age of the patients. ${ }^{8}$ There was no difference in the baseline $\mathrm{FEV}_{1}$ values during the whole study $\left.(\mathrm{p}>0) \cdot 1\right)$ and there was no bronchodilatation 30 minutes after inhaling verapamil, cromoglycate, or saline. The mean provocation dose of methacholine increased significantly with saline, verapamil, and cromoglycate compared with the preliminary baseline bronchoprovocation (Table 3). The PD20 on the day of administration of verapamil compared with the

Table 3 Baseline PD20 FEV, and PD20 FEV, after inhalation of placebo (saline), verapamil, and sodium cromoglycate in the 15 patients

\begin{tabular}{llccc}
\hline $\begin{array}{l}\text { Case } \\
\text { No }\end{array}$ & Baseline & Saline & Verapamil & $\begin{array}{l}\text { Sodium } \\
\text { cromoglycate }\end{array}$ \\
\hline 1 & & & & 150 \\
2 & 60 & 65 & 210 & 43 \\
3 & 80 & 120 & 82 & 130 \\
4 & 18 & 67 & 155 & 32 \\
5 & 72 & 97 & 85 & 135 \\
6 & 55 & 230 & 180 & 70 \\
7 & 25 & 47 & 57 & 58 \\
8 & 45 & 60 & 245 & 14 \\
9 & 16 & 23 & 30 & 112 \\
10 & 85 & 82 & 143 & 430 \\
11 & 85 & 102 & 325 & 510 \\
12 & 95 & 130 & 220 & 145 \\
13 & 83 & 135 & 150 & 17 \\
14 & 42 & 235 & 315 & 275 \\
15 & 15 & 50 & 170 & 85 \\
Mean & 18 & 265 & 300 & $147 \cdot 1$ \\
SD & 52.9 & 113.9 & $178 \cdot 4$ & $147 \cdot 9$ \\
\hline
\end{tabular}

PD20 $=$ Provocation dose that produced a $20 \%$ fall in $\mathrm{FEV}_{1}: \mathrm{FEV}_{1}=$ forced expiratory volume in one second. Significance by Wilcoxon test of pair differences: baseline $v$ saline, $p<() \cdot 01$; baseline $v$ verapamil. $p<(0) \cdot(0)$ : baseline $v$ cromoglycate, $\mathrm{p}<(0.01$ : saline $v$ verapamil. $\mathrm{p}<0.01$ : saline $v$ cromoglycate, $\mathrm{p}>0.05$; verapamil $v$ cromoglycate, $\mathrm{p}<0) \cdot(0)$.

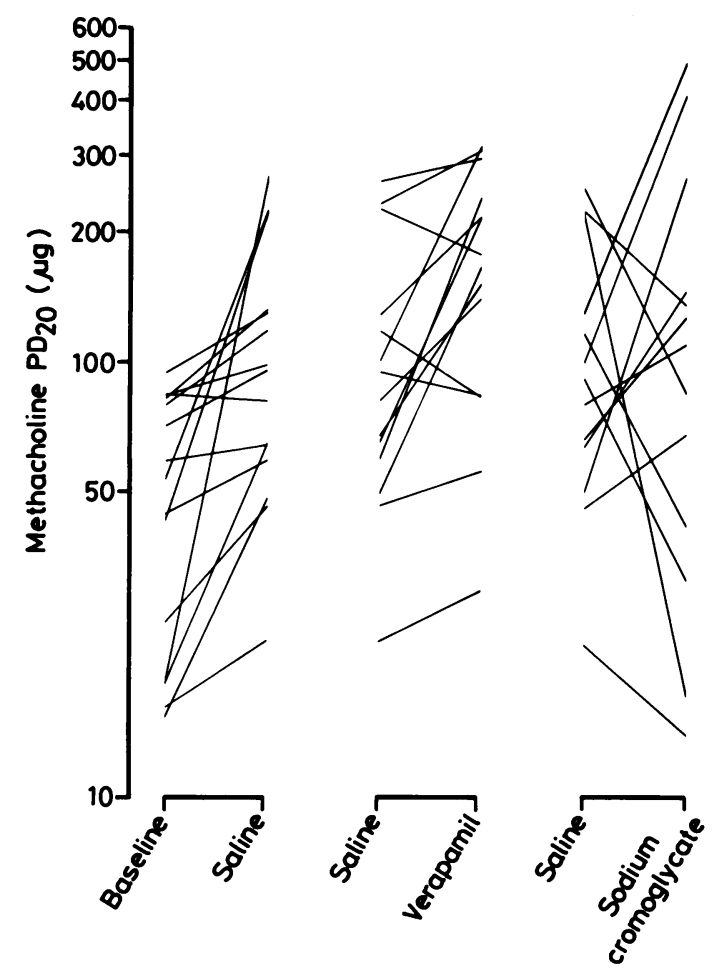

Figure Influence of nebulised sodium cromoglycate and verapamil on methacholine bronchoconstriction (PD20) in 15 children with asthma.

saline was increased in 12 and decreased in three of the 15 patients and on the day of administration of cromoglycate was increased in eight and decreased in seven. Although the mean PD20 increased on the day when verapamil was given and on the day when cromoglycate was given, this increase was significant compared with saline only for verapamil and not for cromoglycate (Figure and Table 3 ).

\section{Discussion}

Verapamil but not cromoglycate given by inhalation reduced sensitivity to methacholine significantly in our patients with extrinsic asthma. Other published studies have produced widely differing results on the degree of protection afforded by cromoglycate or calcium antagonists on bronchoconstriction provoked by cholinergic agents.

Ryo and coworkers failed to show a significant change in responsiveness of airways to methacholine after inhalation of cromoglycate, ${ }^{9}$ and other authors have shown similar results with bronchoprovocation with histamine. ${ }^{10}$ Fabbri and coworkers found that a 
high dose of $40 \mathrm{mg}$ of cromoglycate had a significant protective effect on the bronchial response to inhaled carbachol in six of eight patients tested, ${ }^{11}$ while Patel recently reported that neither low nor high doses of cromoglycate protected the patients challenged with methacholine or histamine. ${ }^{12}$ It has been suggested that the differing results of the studies of inhalation of cromoglycate on bronchospasm induced by histamine and methacholine may be explained by a variable bronchodilator effect of cromoglycate. ${ }^{13}$ We were unable to show a bronchodilator effect of either cromoglycate or verapamil, perhaps because the patients had optimal lung function at the beginning of the study. Our findings on protection with cromoglycate are similar to those reported by Woenne and coworkers. ${ }^{14}$ They found that some patients were protected by cromoglycate, although the effect was not significant when statistical methods were applied to the study group as a whole.

Our observations are at variance with the findings reported by Patel, who showed no significant effect on bronchial reactivity induced by methacholine using verapamil in the same dose in adult patients with asthma. ${ }^{15}$ Other studies have shown a wide range of effects of various calcium antagonists on bronchoconstriction induced by histamine, methacholine, exercise, hyperventilation, and antigen. ${ }^{16}$ The discrepancies in results from various trials may be because the action of calcium antagonists may be dose dependent. In fact, the inhibitory activity of the calcium channel blockers have been shown to vary with the intensity of provocation and the dose of antagonist used. For instance, at low concentration $\left(10^{-7} \mathrm{~m}\right)$ acetylcholine was shown to cause voltage dependent calcium influx into canine tracheal smooth muscle, and this effect was inhibited by verapamil. ${ }^{17}$ At high concentration $\left(10^{-4} \mathrm{~m}\right)$ acetylcholine seemed to produce calcium entry independent of voltage, which was not blocked by verapamil. ${ }^{16}{ }^{17}$ Similar effects may occur in vivo. Doses of bronchoconstrictor agents used in the various clinical studies, however, cannot be compared easily because techniques of challenge and agents differed. Walters et al showed that the bronchoconstrictor effect of low concentrations of inhaled histamine was amenable to the inhibitory effect of verapamil but that once bronchoconstriction had occurred with higher doses of histamine the reactivity of airways was actually increased by verapamil. ${ }^{18}$

Other explanations for the variation in results may have been the utilisation of different methods of bronchoprovocation; varying age of the patients, severity of asthma, and its treatment before the study; and differing methods of statistical analysis. It is clear that bronchial hyper-reactivity is profoundly affected by the severity of asthma and can be decreased by effective treatment with either cromoglycate or inhaled steroids. Our patients had rather more severe asthma than is usual in patients chosen for challenge studies. We were able to conduct the study on these patients only because they were resident at high altitude, which resulted in improved control of their asthma. ${ }^{5}$

Free calcium ion availability in smooth muscles and mucous glands is thought to be a critical final pathogenetic pathway in asthma. ${ }^{19}$ It follows, therefore, that reduction of calcium availability to essential contractile and secretory functions would be effective therapeutically. It is unlikely that they act by stabilising mast cells, as was hypothesised in earlier studies. A direct effect on the irritability of airway smooth muscles by limiting free calcium ion availability is an attractive alternative explanation.

There is now a large bibliography on the inhibitory effects of single doses of calcium antagonists on artificially induced airflow limitation in subjects with asthma. Extrapolation of the results of such studies to the clinical situation is often misleading, as is apparent from the apparent lack of effect, in our study, of the often clinically effective drug, cromoglycate. Similar, even more dramatic, discrepancies are observed with corticosteroids. We think that our study on children with moderately severe asthma indicates that clinical investigation of the therapeutic role of calcium antagonists is now required.

\section{References}

I Curry JJ. Comparative action of acetyl beta methylcholine and histamine on the respiratory tract in normals, patients with hay fever and subjects with asthma. J Clin Invest 1947:25:430-8.

2 Boushey HA, Holtzman MJ, Sheller JR, Nadel JA. Bronchial hyperreactivity. Am Rev Respir Dis 1980;121:389-413.

3 Juniper ET, Frith PA, Dunnett C, Cockcroft DW, Hargreave FE. Reproducibility and comparison of responses to inhaled histamine and methacholine. Thorax 1978;33:705-10.

4 Vervloet D. Penaud A, Razzouk H, et al. Altitude and house dust mites. J Allergy Clin Immunol 1982;69:290-6.

5 Boner AL, Niero E. Antolini I, Valletta EA, Gaburro D. Pulmonary function and bronchial hyper-reactivity in asthmatic children with house dust mite allergy during prolonged stay in the Italian Alps (Misurina, m. 1756). Ann Allergy 1985;54:42-5.

${ }^{6}$ Porter CJ, Garson A, Gilette PC. Verapamil: an effective calcium blocking agent for pediatric patients. Pediatrics 1983;71:748-55.

${ }^{7}$ Rosenthal RR. The emerging role of bronchoprovocation. $J$ Allergy Clin Immunol 1979;64:564-8.

* Polgar G, Promadhat V. Pulmonary function testing in children. Techniques and standards. Philadelphia: W B Saunders, 1971: 87-212.

9 Ryo UY, Kang B, Towley RG. Cromolyn therapy in patients with bronchial asthma. Effect on inhalation challenge with allergen, histamine and methacholine. JAMA 1976;236: 927-31. 
10 Cockcroft DW, Killan ND, Mellow JJA, Hargreave FE. Protective effect of drugs on histamine induced asthma. Thorax 1977:32:429-37.

"Fabbri LM, Mapp CE. Hendrick DJ. Effect of cromolyn on carbachol-induced bronchoconstriction. Ann Allergy 1983;50:195-8.

12 Patel KR. Sodium cromoglycate in histamine and methacholine reactivity in asthma. Clin Allergy 1984;14:143-5.

13 Jones RM. Horn CR, Lee DV, Brennan SR. Bronchodilator effects of disodium cromoglycate in exercise-induced bronchoconstriction. Br J Dis Chest 1983;77:362-9.

14 Woenne R, Kattan M, Levison H. Sodium cromoglycate induced changes in the dose-response curve of inhaled methacholine and histamine in asthmatic children. Am Rev Respir Dis 1979;119:927-32.

15 Patel KR. The effect of verapamil on histaminc and methacholine-induced bronchoconstriction. Clin Allergy $1981 ; 11: 441-7$.
16 Barnes PJ. Calcium channels blockers and asthma. Thorax 1983;38:481-5.

17 Farley JM. Miles PR. The source of calcium for acetylcholineinduced contractions of dog tracheal smooth muscle. J Pharmacol Exp Ther 1978;207:340-6.

18 Walters EH, Banks J, Fennerty A, Davies BH. Effects of calcium channel blockade on histamine-induced bronchoconstriction in mild asthma. Thorax 1984;39:572-5.

19 Townley RG. Calcium channel antagonist in coronary artery spasm and bronchial asthma. What do variant angina and bronchial asthma have in common? Chest 1982;82:401-3.

Correspondence to Dr J O Warner, Pacdiatric Respiratory Unit, Brompton Hospital. Fulham Road, London SW3 6HP.

Received 8 October 1986

The author described his observations on 24 African children aged from 1 to 4 years who were admitted to hospital in Nairobi. Clinical features included misery, irritability, anorexia, and extreme listlessness. Oedema was universal, usually severe and generalised, and if it disappeared great emaciation was revealed. Skin manifestations included jet black areas of hyperkeratosis, which showed a tendency to exfoliate, disclosing areas of pink or pale skin. Sodden areas of heaped up white skin or excoriation were seen near mucocutaneous junctions (mouth, nose, canthi, and anus). Fissures, often deep and linear, developed at the flexures. Generalised hypopigmentation was usual. The hair came out easily, was thin and brittle, and changed colour. Septic skin lesions were common. All cases were associated with diarrhoea, and steatorrhoca was pronounced in most. Neurological changes were rare apart from hypotonia and wretchedness, but eight patients exhibited hypertonia, increased tendon reflexes, and extensor plantar responses. Another common finding was photophobia with red eyes. In most children there was a microcytic hypochromic anaemia; in three a macrocytic anaemia was found.

In his discussion Trowell noted that the clinical and laboratory features, particularly the pronounced oedema, distribution of the skin lesions, steatorrhoea, and rarity of neurological signs differed from the classical description of pellagra in adults and he was aware that other workers in tropical Africa had concluded that the disease under study was not pellagra. He maintained, however, that this syndrome in young children did reveal the main clinical signs of pellagra, and he observed that other known deficiency states-for example, scurvy, and rickets/osteomalacia-display a different clinical picture in children and adults. Indeed he stated, "It is not suggested in this article that the disease is anything but pellagra”.

Comment. Fifty years ago there was much confusion about the nature of the disorder as described by Trowell and others on the east coast and the disorder described by Cicely Williams and others in west Africa. Today Trowell's patients would be accepted as undoubted examples of kwashiorkor and the confusion has long since been resolved. It should be remembered, however, that it is possible for pellagra to coexist with kwashiorkor. Furthermore, the manifestations of kwashiorkor may differ in various geographical areas due to superimposition of additional deficiencies-for example, B complex, vitamin A, iron, and folic acid. 